\title{
The Rise and Fall of the Jumbo Breakfast Roll: How a Sandwich Survived the Decline of the Irish Economy
}

\author{
by Perry Share \\ Institute of Technology, Sligo
}

Sociological Research Online, 16 (2) 2

<http://www.socresonline.org.uk/16/2/2.html>

$10.5153 /$ sro. 2289

Received: 13 Jan 2011 Accepted: 30 March 2011 Published: 20 May 2011

\section{Abstract}

This paper examines a specific food item - the Jumbo Breakfast Roll [JBR] - through a sociological lens, in order to trace the factors that contributed to its rise to prominence in Irish food culture in the 'Celtic Tiger' period of the late 20th/early 21 st century. It also examines the development of these factors in the period following the crash of the Irish bubble economy. It is argued that the JBR arose at the intersection of a number of key trends in the food technology, retail, transport, distribution and construction sectors. Yet the JBR also had its antecedents in established foodways and traditions. It reflects on how the JBR could be interpreted as a 'national dish' that symbolised a particular moment in contemporary Irish society, and raises the possibility that a sociologically-informed analysis of such emblematic dishes allows us to explore aspects of national society, culture and economy within a globalised world.

\section{Keywords: Fast Food; Ireland; Culture; Economic Conditions; Celtic Tiger; Convenience Stores; Baking Technology; Sandwich}

\section{Introduction}

1.1 In late November 2010 the era of Ireland's 'Celtic Tiger' bubble economy formally came to a dramatic and ignominious end. In front of the watching cameras of the world's media, the personnel of the International Monetary Fund, the European Central Bank and the European Commission came to Dublin to negotiate and subsequently announce a financial 'bailout' of (initially) €85bn. After a rather protracted period of decline, the Celtic Tiger economy was pronounced well and truly dead.

1.2 In 2008 I suggested (Share 2008) that Celtic Tiger Ireland had generated a food product - the Jumbo Breakfast Roll [JBR], described in detail below - that reflected the economic boom and the 'new Ireland' that had emerged from decades of underdevelopment. I went so far as to suggest that the JBR could be labeled Ireland's 'national dish', not in the sense that it was the most commonly consumed foodstuff, nor that it could claim any particular authenticity within a real or imagined 'national cuisine', rather that it was emblematic of the key trends and trajectories within contemporary Irish society. It was a rhetorical device similar to that wielded by then British Foreign Secretary Robin Cook when he suggested, in a speech in 2001, that Chicken Tikka Masala could claim to be Britain's 'national dish' ('Robin Cook's chicken tikka masala speech', Guardian, 19 April 2001) a claim that continues to generate discussion.

1.3 This article outlines the argument for the JBR's uniquely symbolic character, from a broadly sociological perspective within food studies. The significance of the JBR was drawn from its high-profile popular cultural recognition; its unique positioning at the intersection of technological, infrastructural, cultural and financial trends; its origins in real and manufactured culinary authenticities; and its implication in a perceived lifestyle of increasingly 'disordered eating'. The article outlines the popular cultural emergence of the JBR; briefly outlines the nature of the product itself; relates its apparent decline to the changing economic climate; and then traces the fate of the key cultural, technological, consumption trends that saw the JBR come to prominence, and have been implicated in its subsequent decline.

1.4 The article draws on secondary sources of evidence, and does not involve an ethnography or survey of JBR consumers. It looks to the food industry and food service trade literature, to artefacts of popular culture, to financial and statistical data and to sources in Irish and international food history. It does not claim to be a full account of the social context and impact of this particular food product; rather its aim is to outline how use of a 'sociological lens' or sociological imagination can perhaps draw our attention to the complexity and interest of an everyday item of consumption that may otherwise evade social analysis (see, for example, Miller 2010; Shove at al 2007).

\section{JBR as Celtic Tiger food}

2.1 The JBR emerged publicly into Irish popular cultural consciousness through two specific cultural phenomena. On 6 January 2006, as the Irish bubble economy reached its zenith, a well-known comedian, Pat Shortt, went on to Ireland's most popular television show, the Late Late Show and, in his persona of faded showband star Dixie Walsh, performed his new song 'Jumbo Breakfast Roll' (RTE 2006). It subsequently became the top-selling pop single of that year though, given its local sphere of reference, did not impact on any other nation's popular music market. Replete with references to building-related phenomena ('luminous jackets'; 'chippies' [carpenters]; 'sparkies' [electricians]; 'working up a ladder') the song's refrain efficiently lists the key components of the JBR:

Two eggs two sausage two rasher two bacon two puddin' one black one white All stacked like a tower on top of each other and rolled up good and tight If you're having some tea the milk's over there and sugar in a bowl Says she 'Do you want some sauce on that?' says I, 'I do in my roll'. (leoslyrics.com (no date) 
2.2 The other key cultural reference was in the work of Ireland's best known popular economic commentator David McWilliams who, in in his best-selling book The Pope's children (McWilliams 2005), celebrated 'Breakfast Roll Man' as an emblematic figure of the over-heated, construction-fixated Irish economy: he was a harried and hurried sub-contractor always on the move, whose normal location was in the cab of his van, inching along one of Dublin's poorly planned ring-roads to yet another building site, pausing only to refuel both vehicle and man on one of the 'Emo, Statoil, Shell forecourts' referred to in Shortt's song. Such was the power of McWilliams's imagery that 'Breakfast Roll Man', as personification of the influential construction sector, was popularly credited by the mass media with winning the 2007 general election for the Fianna Fáil party, the political force most closely associated with property development.

2.3 The JBR has thus a particular cultural resonance with a very specific period of recent Irish history: the over-heated boom economy of the middle of the first decade of the twenty-first century. It is unusual for specific foodstuffs to come to such prominence in Irish cultural discourse, apart from the ubiquitous linking of the potato (and associated Great Famine) with the Irish nationalist narrative. In recent decades indigenous commercial products such as Harp Lager and Jacob's biscuits and, of course, Guinness stout, have had a strong cultural presence, often supported by long-running advertising campaigns. In 2010 a theme park dedicated to another iconic food product, Tayto Crisps, opened in Ashbourne, Co. Meath and a biography of 'Mr Tayto' sat at the top of the bestseller lists for six weeks in late 2009/early 2010. None of these products has been as clearly identified with a specific historical period, economy and milieu as the JBR.

\section{What is the Jumbo Breakfast Roll?}

3.1 The JBR, briefly, is a collation of hot pork products, placed in a par-baked 'baguette' or 'demi-baguette' bread roll and dressed with tomato ketchup or brown sauce. The ingredients typically include at least some of (and ideally all of) fried or grilled Irish-style pork sausages, bacon rashers, white and/or black (blood) pudding and fried egg. These may be accompanied by other ingredients such as fried or grilled mushrooms, baked beans or even coleslaw. The whole construction is then wrapped in tin-foil, for later peeling off during consumption, which may in turn be wrapped in plastic cling-film. The JBR may be consumed by itself, or with chips or crisps, and washed down with tea, cold milk straight from the carton, or a soft drink such as Coca Cola or Lucozade.

3.2 The JBR has always been closely associated with the mobile construction industry workforce. Typically it is purchased at a 'deli' counter in a convenience (or c-) store, often located on a petrol station forecourt. Like the related 'all day breakfast' its consumption is not confined to the morning, but can take place at any time of the day. It is also a popular school lunch option, with convenience stores and cafés close to schools offering very reasonably priced options, and it is also recognised as a late-night, post-drinkingsession dish or hangover 'cure'. The food service and retail industries have recognised the JBR as a highcalorie product aimed at a rural, male, working class, younger (up to age 44) clientele (Amárach Consulting 2007, p. 9).; female and more up-market consumers are targetted with 'healthier options' such as 'wraps'.

3.3 The JBR appears to be a uniquely Irish product, though it does have close relations amongst other rollbased hot sandwiches in other parts of the world: such as the Vietnamese Bánh Mi, the (vegetarian) Maharashtran Vada Pav, the Tex-Mex (Jumbo) Breakfast Burrito, the British bacon (and egg) sandwich, stottie or buttie, the Philadelphian Hoagie, the Belgian Mitraillette and even the McDonald's Egg McMuffin. Many, though not all, of these food items are predominantly consumed at breakfast time, or what the food service industry refers to as the 'breakfast daypart'. But the particular constellation of elements (such as the use of the par-baked demi-baguette; the foil wrapper, the white pudding) in the JBR does make for a distinctively 'national' food product, one that is recognisably 'Irish'. These component parts are further discussed below.

3.4 Wilson (2010) notes that many types of sandwich are regional specialities, only recognised or celebrated in a specific locale and often marked through a specific flavour, condiment or other 'ethnic' marker. A similar point is made by Maroukian (2009) particularly in relation to how ethnic minority groups can use the sandwich as a quick and easy way 'to quickly set up shop and fold(ed) their native ingredients (and/or cooking methods) into mainstream cuisine'. Many of these 'new' sandwiches never travel beyond a particular deli or street vendor; others may subsequently become more widely commercialised within a specific region (eg the Hoagie) while a select few (such as the BLT) achieve global prominence (arguably now taking place with the Bánh Mi) often through linkages with a global diaspora or a globalised food firm. As of yet there is little indication that the JBR has moved outside of the Irish national arena, unlike the 'bookmaker's sandwich' (a steak in a loaf of bread, effectively) which has become a staple menu item amongst some 'Irish' pubs in the US and Ireland itself. In the UK Cornish baker Ginster has released an 'All day breakfast roll' pre-packaged product that does share some of the features of the JBR, though it has no 'Irish' identification.

3.5 It is often the case that the emergence of a specific 'national' food item is associated with a 'creationist' origin myth - which is often contested. The pavlova meringue-based dessert dish, for example, has been claimed by both the Australians and the New Zealanders. The former claim it to have been 'invented' by a particular individual chef - Herbert Sachse - in 1935 while New Zealanders claim there is evidence that the dish, or something very like it, was extant in their country prior to this date (Leach 2010). Similarly the claim that the sandwich was 'invented' by John Montagu, the Fourth Earl of Sandwich, is open to debate, as it was very likely that the act of putting a slice of meat between two of bread had occurred prior to 1762, the reputed year of the sandwich's creation (Wilson 2010). Nevertheless such origin myths allow for the subsequent creation of more extensive narratives associated with the food in question, while allowing for nationalistic debate to take place (see for example the tussle over the origins - Scottish or Indian? - of the chicken tikka masala, Pakistan Daily 7 August 2009).

3.6 It has been claimed that the Irish breakfast roll (not yet 'Jumbo') was 'invented' in 1992 by Mick Flynn, a manager with the Norwegian oil company Statoil, then a major petrol station operator in Ireland, and innovator in the development of forecourt retail operations. According to Flynn:

at the time, there was nothing around where you could eat a breakfast on the go, something you could take with you in your car ... I was store development manager in 1992, and we were developing a complete concept with the shops, and putting food in as the number one item in our station. It took off from day one, and they're even writing songs about it now. It's an unbelievable seller. It started off as bacon and a sausage in a roll. Now they're putting egg in it in some places (Carswell 2007)

3.7 It was reported that the first (jumbo) breakfast roll was sold at a Statoil petrol station in the town of Bray, south of Dublin. The JBR was first mentioned in the Irish Times newspaper in 2000, and by 2003 it was being criticised for having contributed to the 'McDonaldisation of breakfast culture' (Derek O'Connor Irish Times 7 August 2003).

\section{The decline of the JBR?}


was particularly linked with the construction industry, and those (young, male, affluent, mobile) who worked in it - an unprecedented $20.5 \%$ of the Irish male workforce in mid-decade (CSO 2006). That industry has now gone into catastrophic decline, with a shrinkage in the employed male workforce from a quarter of a million in 2006 to barely over one hundred thousand in late 2010 (CSO 2010a), a decline of almost 58 per cent in less than four years. The frenetic construction activity of the mid-2000s has been replaced with talk of giveaway apartments and 'ghost estates' - ranks of empty houses that nobody wants or can afford (Kitchin et al, 2009). In the period 2006-2009 there has been a 9\% decline in national GDP and the unemployment rate has increased, from 4.8\% in January 2008 to 13.5\% in October 2010 (CSO 2010b). Incomes of those in work have been fairly static over that period, though the overall figures hide large sectoral differences. There has also been a significant return to outward migration, with a return to figures (an excess outflow of $c$. 100 people a day) not seen since the late 1990s (CSO 2010c).

4.2 Playwright and columnist Michael Harding remarked on the cultural manifestation of these changes in late 2008:

I was out early one morning, and I found a small cafe that still serves breakfast rolls to the early birds, though there are no queues now - no men in yellow jackets or building boots covered with yesterday's cement. The young Polish man behind the counter used to know them all by name, but he doesn't know where they all went (Michael Harding, Irish Times 21 Nov 2008)

4.3 Unfortunately it is not possible to obtain overall figures for the consumption of breakfast rolls per se., either at their peak or subsequently. As they are combined from a number of separate components from different suppliers, they are not captured in distributor figures. At the same time, they do not feature as a specific identifiable item in official food consumption surveys. But it is clear from the statements by food service industry representatives (in the trade press and at industry briefings), and by observation, that the pre-eminence of the JBR has passed.

4.4 Ironically, just as the consumption of breakfast rolls has apparently peaked, they have been institutionalised by a branch of the Irish state. At a planning hearing into the construction of new motorway service areas, the National Roads Authority indicated that concessions at the service areas had to provide a 'full breakfast, "including breakfast rolls" ...(as well as) a "healthy breakfast alternative"' ("Breakfast Roll Man gets grub guarantee' Irish Independent 9 July 2008). It is through such institutional statements and actions that menu items such as the JBR, or the Chicken Tikka Masala, become identified as constitutive of national cuisines and incorporated into national food discourses.

\section{Deconstructing the JBR}

5.1 The JBR emerged as the consequence of the intersection of a number of technological, cultural and economic trends. These help to explain the appearance of this particular food product at this time (den Hartog 1995). The most salient components include the bread roll, and the par-bake technology used to produce and distribute it; the pork products within the roll, and the preeminence of pork within Irish foodways; the particular place of convenience or c-stores on the Irish retail landscape; and the potentially 'disordered' nature of Irish eating behaviours, buttressed by a mobile and dispersed population. Each element helps to illuminate the emergence of the JBR at this sociological and historical juncture.

\section{The bread roll}

5.2 The initial and crucial element of the JBR, or indeed any sandwich, is the bread (Wilson 2010). The JBR has been made possible as a result of the remarkable success of the Irish par-baking industry, which itself is part of the larger success story of the globalising Irish food and agribusiness industry.

5.3 Typically the JBR is composed within a $c .15 \mathrm{~cm}$ long 'demi-baguette' produced by the IAWS food conglomerate (now part of an even larger conglomerate, Aryzta). IAWS (originally the Irish Agricultural Wholesale Society) is a Dublin-based company with its origins (like many Irish food corporations) in the rural cooperative movement. In 1997 IAWS acquired the successful Cuisine de France bakery company (Cuisine de France 2010) which had pioneered the large-scale production, distribution and marketing of partially-baked 'French' bread, first in Ireland and later in the UK, Europe and the US.

5.4 Cuisine de France benefitted from the move towards 'real' 'artisan' bread that accompanied the rejection, amongst some consumers, of the ubiquitous 'white sliced pan' produced by the Chorleywood Bread Process. The par-baking process entails the centralised production and subsequent delivery of partially-baked, frozen bread loaves (particularly baguettes, 'demi-baguettes' and crusty rolls) to retailers, who then finish the baking in small store-based ovens to offer consumers the 'fresh-baked bread' experience. It offers the illusion of local 'artisan' bread production without the need for any local artisans the bread can be finished by low-paid unskilled store operatives, with no need for a kitchen or bakery area and with little waste as the par-baked loaves can be stored until required. Cuisine de France displays are now very familiar to Irish consumers and are particularly associated with convenience stores and petrol station forecourts - the natural home of the JBR.

\section{Pork and the 'Full Irish'}

5.5 In December 2008 the actions of a single animal food manufacturer closed down the entire Irish pork industry: constituting a severe, if short-lived, threat to to the JBR. As a consequence of dioxin contamination of animal feed, there was an international recall of Irish pork products from 23 international markets and, at the same time, all pork, bacon, ham and sausages disappeared from Irish supermarkets, convenience stores and petrol station forecourts (Boucher-Hayes \& Campbell 2009: pp. 188-192). A subtantial number of these would have been manufactured and distributed by Carroll Cuisine: another part of the IAWS empire ('Carroll Cuisine back in business', Offaly Express, 23 December 2008).

5.6 This 'national crisis' pointed not only to the importance of the €300m Irish pigmeat industry, but also to the centrality of pork in Irish cuisine and culture. Pigmeat has been part of the Irish diet since the earliest food records and the Irish people have long been enthusiastic consumers of pork and related products (Sexton 1998, p. 44). Sausages, bacon rashers, sliced ham, ham 'gammon' steaks and black and white pudding are widely consumed today. The only detailed nationwide survey of food consumption in Ireland to date (IUNA 2001) found that, in the survey period, a clear majority of people had consumed sausages and 'ham and bacon' products; of men aged 18-35 72\% had consumed the former, while $81 \%$ had eaten the latter (IUNA 2001, Table 2.5)

5.7 The specific combination of pork products that constitutes the JBR derives directly from another key aspect of Ireland's 'food heritage': the 'Full Irish (breakfast)' - one could define the JBR as 'a Full Irish in a roll'. Like many 'traditional' and 'authentic' food products the Full Irish breakfast (like the 'English breakfast') is largely an invention of the early twentieth century. Its emergence mirrors the development of another emblematic aspect of Irish culture, and specifically its tourist industry: the B\&B (bed and breakfast), where the Full Irish Breakfast is de rigeur. Unlike its counterpart in the US and Australia, the $\mathrm{B} \& \mathrm{~B}$ in Ireland has traditionally been a more downmarket accommodation option found in rural areas, country towns, villages and suburban settlements, such as the one where French anthropologist Jerome 
Martin (2004, p. 18) had his first encounter with the Irish breakfast:

I arrived in front of a house situated in Lucan [Dublin suburb] in a very cosy estate. The house was really similar to all the others right beside it, except of course for the little sign announcing it was a B\&B. I literally spent these days sharing the life of a single old woman who transformed the rooms of her children, now gone, into rooms to rent. I also discovered for the first time the concept of the Irish breakfast. For an Irish person, or even for me now, the remark can appear as quite surprising, but at this period the shock of eating this salty fat food in the morning was very real. At 8 o'clock in the morning having to eat an egg, two slices of bacon, two spicy sausages, a fried tomato, white beans served in a curious sweet tomato sauce and slices of a fried dark thing called pudding, was truly at the limits of the possible.

5.8 The origins of the 'Full Irish' are unclear. Its close cousin the cooked 'English Breakfast' has been described by food historian O'Connor (2006, p. 4) as 'a culinary mystery'. Both involve a lot of meat, principally pork products. This suggests their genesis as a popular meal is relatively recent, as meat has only come to dominate the diets of the majority in these islands, as in many European societies, since the mid-nineteenth century (Clarkson and Crawford 2001, p. 106; Pilcher 2008, pp. 25-26). Prior to the economic growth that accompanied the expansion of industrial capitalism and the British Empire, the majority of the Irish population breakfasted, if at all, on bread, oats or potatoes, often cold leftovers, accompanied by water, milk, tea or beer.

5.9 It has been suggested (O'Connor 2006) that the English 'cooked breakfast' is derived from the breakfasts that the landed gentry consumed from about the mid-seventeenth century onwards: lengthy, masculine affairs that featured offal, game, fish, pies and other heavy foods, as well as fruits, breads and preserves. As part of the 'civilising process' this meal was gradually lightened and spread into the aspiring upper and middle classes, shrinking in extent and complexity until it developed by the mid-nineteenth century into the relatively standardised 'cooked breakfast' we are familiar with today. A similar process occurred in Ireland, where the cooked breakfast made its appearance in the households of the Protestant Anglo-Irish Ascendancy and the large farmers, before diffusing amongst the broader rural population. In Britain, by contrast, a hot breakfast seems to have made an earlier appearance amongst at least some of the (wealthier) elements of the working class, reflecting a greater level of wealth in the centre of the Empire. It even generated a precursor of the breakfast roll, as reported by Victorian food historian Andrea Broomfield (2007, p. 26): she reports that in northern Britain roadside vendors would set up stalls on the routes to factories, where:

soft large rolls [presumably a stottie, bap or similar] ... were popular with labourers because they were cheap and designed to hold a ham, fried egg, or sausage filling. After swallowing a mug of coffee and returning the mug to the vendor, the labourer continued on to work while eating breakfast.

\section{C-Stores}

5.10 A third key element in the story of the emergence and success of the JBR is the strong position of the convenience store or, in industry parlance, the 'c-store', within the Irish retail sector and the Irish community. It is at the so-called 'symbol' c-stores, rather than conventional cafés, supermarkets or sandwich outlets, that the JBR is consumed. These stores - there are 5300 of them in Ireland (Swain 2010) - are typically located in the main streets of country towns, in some suburban areas, on the main routes into the cities and, crucially, on petrol station forecourts.

5.11 C-stores account for just over 5\% of the total grocery 'spend' (Swain 2010), with a focus, not surprisingly, on 'convenience' or 'top-up' items such as bread, milk and tea. About half of such stores are independents, while the remainder are in the expanding sector of 'symbol' stores - which may be wholly owned, franchised or licensed operators under a variety of brandnames (such as Centra, Mace, Gala).

5.12 The strength and dynamism of the c-store sector in Ireland may reflect the strong indentification with the 'local' and the 'community' that continues to pervade - especially rural - Irish life. This is manifested in the political system; in the strength of the Gaelic Athletic Association (the national amateur sports organisation for gaelic football, hurling and handball); and in the still considerable local role of the Catholic and other churches. Local shops continue to provide a node for social interaction and exchange of information; local newspapers, still important in Ireland, are prominently on display and, notwithstanding the employment of a significant number of recent immigrants, such stores provide an important source of employment for local people, including weekend work for students.

5.13 The persistence of the c-store sector is also predicated on the application of the Irish planning laws. While the lax application of planning legislation has been recognised as a key source of Ireland's current economic problems, it has been successful in thwarting, to some extent, the type of out-of-town retail development that has contributed to the decline of village and town centres in the UK and the United States (Steel 2009, pp. 140-144). As in many EU countries, there is a tradition in Ireland of restriction on large-scale supermarket development and this has been underpinned by the relative strength of the grocers' lobby group RGDATA. In 2005 the government's retail planning guidelines (Government of Ireland 2005) reinforced the 1998 restriction on the construction of supermarkets with a floor space in excess of $3,000 \mathrm{~m}^{2}$ in order to facilitate development 'of a scale which allows the continued prosperity of traditional town centres and existing retail centres'.

5.14 The success of forecourt operations reflects the highly mobile and car-dependent nature of Irish society. Ireland has one of the most car-dependent capital cities in Europe, while Irish people are amongst the most likely to drive to work rather than use public or alternative forms of transport (Wickham 2006). The fastest growing type of c-store is that located on the petrol station forecourt. Recent rationalisation of the fuel sector has seen the emergence of much larger, more sophisticated forecourt operations, where fuel retailing is typically combined with a c-store, restaurant, deli, ATM and other services. It is usual now for forecourts to derive greater profits from the 'ancillary' aspects of the business, rather than the relatively low-margin fuel business. There is a blurring of the retail and food service activities of c-stores. This has interacted with the new forms of Irish mobilities, as pointed out in 2005 by the industry Checkout magazine:

the choice of where to stop to buy fuel is increasingly influenced by the quality of the food and drink offer. Compound this with the fact that $70 \%$ of us have breakfast alone Monday to Friday, the forecourt has become a place to start the day. Not only do we find ourselves on the road much earlier in the morning in order to beat the traffic, increasingly we are driving through traditional lunch hour and evening dinnertime to get home again. With so much time spent in the car it is not surprising that customers are looking for - nay, depending on quality food and drink offers to cheer up their day (Bradley 2005).

5.15 Since the onset of the economic recession in Ireland there has been a decline in the expansion of the $c$-store sector. In 2009-2010 the number of outlets declined by $4.4 \%$. There is evidence that consumers are, to an extent, eschewing 'convenience' and impulse buying and moving towards larger multiple retailers 
(ie supermarkets). The c-stores have responded by trying to make themselves more like supermarkets, with the introduction of special offers and an increased number of 'own brand' products (Swain 2010; Berry 2010). On the food service front there has been a move away from the targetting of the male market for breakfast rolls towards a more feminised market for 'healthy' options such as sandwiches and wraps.

\section{Disordered eating?}

5.16 The final piece in the JBR puzzle is the increasing trend that has been identified in Ireland towards 'disordered eating', a term derived from psychology but which can now be taken to represent a powerful medico-social disourse on a broader level. As in other anglophone countries there continues in Ireland to be something of a moral panic in relation to contemporary eating habits, with popular and academic concern in relation to family eating patterns, the apparent decline in commensality (eating together), 'dashboard dining', the impact of television watching, snacking and fast food, obesity and the decline in food knowledge (Boucher-Hayes \& Campbell 2009, Gard \& Wright 2005). There has been little published research into Irish everyday food practices, as opposed to analyses of consumption or nutritional intake. Overall it has been suggested that Irish people exhibit food consumption patterns similar to those found in other Anglophone countries, such as the UK and Australia (The Futures Company/Bord Bia 2009, slide 6). Inspired by the writings of French sociologist Claude Fischler and colleagues (Fischler \& Masson 2008) and American food writer Michael Pollan (2007), many analysts have sought to contrast a continental European food sensibility based on commensality and structured eating events, with an anglophone approach to food that sees it primarily as individual fuel, and that relegates its everyday cultural significance.

5.17 Thus, for example, French anthropologist Jerome Martin completed a doctoral analysis of Irish eating habits - specifically those of university students - in 2004. He records the profound culture shock he experienced on encountering in Ireland a thoroughly disordered approach to food and eating, at least by French standards. Thus, he exclaims: 'in Ireland, from what I could see ... exactly the same food could be served in the restaurants from 11am to 9pm'. He observed school children eating sandwiches and sweets in shops during their lunch breaks, rather than sitting in school canteens; he noted sandwiches in the lunchboxes of primary school pupils that contained 'meat, cheese and veg all together'; and children going straight from school to the chip shop at $2 \mathrm{pm}$ in the afternoon. He was led to conclude that in Ireland:

notions of table, meal and timetable did not ... seem to be linked together in the ... school. Furthermore this triplet did not seem to be either respected as an everyday routine inside the functioning of the family. [Thus] having a meal in Ireland does not seem to be inevitably joined to the idea of sharing a meal, but rather seems to hold the primary function of filling the stomach, and this, at every opportunity (Martin 2004, pp. 35-36)

5.18 It was not rare, he suggested, to see Irish people having six, seven or eight 'food intakes' a day, a figure that could be doubled if one counted teas, coffees and other drinks. The contrast with the clearly structured meals and eating timetables of French culture could not be more stark.

5.19 By contrast, research in rural Northern Ireland (Rugkåsa et al 2006) which the researchers claim ( $p$. 14 ) is transferable across the island as a whole, suggested that participants (all but one of whom were adult women) conceptualise and mobilise food and food events in terms of binary oppositions with a 'very strong social and cultural basis', around 'good'/'bad' food, 'local'/'foreign' food and 'proper'/'junk' food, that may in turn be linked to gender, family and local identity ( $p .6)$. While there is clearly a recognition that relatively unstructured food events such as those identified by Martin do exist, such 'junk' and 'fast' food was associated with the diets of younger more mobile people. Participants particularly valued 'dinners' and even 'big dinners' that involved large quantities of meat and traditional foodstuffs, but also social interaction and commensality:

High value was attached to the sharing of food through eating together. In particular, the importance of eating together with the family was emphasised, and in most households it was the norm, or at least the ambition, that the family would eat their evening meal together (Rugkåsa et al 2006, p. 33)

5.20 A study of Scottish teenagers (Wills et al 2008) - again culturally similar to the Irish - also indicated that even within this group, who were used to individually provided food 'on demand', 'half the participating teenagers reported that they always, or nearly always, ate at the same time, and in the same room, as the rest of their family' (Wills et al 2008: 4.1). It is fair to say that there is much scope for further sociological work on contempoary everyday eating patterns in Ireland.

5.21 The 2007 SLÁN (Survey of Lifestyle, Attitudes and Nutrition) (Morgan et al 2008, pp. 68-70) provides some information on such patterns. Almost half of respondents reported that they ate 'snacks' outside of standard mealtimes, with women $(52 \%)$ reporting more snacking than men $(48 \%)$. Just under half $(45 \%)$ of snacks were reported to have been from the top level of the 'food pyramid' - thus high in salt, fat and sugar. Levels of food consumption outside of the home ranged from $7 \%$ who had consumed breakfast away from home on the day prior to the survey, to $12 \%$ who had consumed their main meal and $23 \%$ who had consumed a 'light meal' away from the home.

5.22 A Bord Bia (2010) investigation of 'out of home breakfast' consumption found that $15 \%$ of adults aged $18-55$ had breakfast 'out' on the survey day, rising to $20 \%$ for $25-34$ year olds. Those most likely to eat breakfast 'out' were male, in full time work, and without children. In social class terms they were most likely to be in class C1 (non-manual workers) and to a lesser extent C2 (skilled manual workers). Unskilled workers and the unemployed are considerably less likely to eat breakfast, or any meal, outside the home. Of those who do eat breakfast outside the home, the average frequency is just once a week. The most likely location of breakfast consumption is reported to be - as suggested above - a sandwich shop, cstore, deli/bakery or garage forecourt with very few making use of supermarkets or fast-food outlets. Of those who do eat breakfast out of home, the breakfast roll (at $32 \%$ ) ranks fourth on the menu, behind cooked meats, eggs and toast and the breakfast roll is the type of breakfast most likely to be eaten 'out' rather than 'in'.

5.23 Overall, this data does not point to an abandonment of the 'traditional family meal' and a rush towards 'dashboard dining' or a chaotic and fractured foodway. It is clear that a segment of the population, disproportionately comprised of younger, single, working males in 'intermediate' social classes, does make the choice to consume meals out of the home, including breakfast, 'elevenses' and lunch, and that more often than not, the location for these food experiences is a c-store or garage forecourt. We know that this group has been severely impacted by the current recession, especially those in occupations within or linked to the construction sector. They will have much less disposable income, and the data reflects that those who are unemployed are significantly less likely to eat out.

\section{Conclusion}

6.1 So, what can we say about the current status of the Jumbo Breakfast Roll? Like many of its global counterparts the JBR has been closely associated with the male, mobile working and service class, often that derived from or located in rural or peri-urban areas. At the peak of its popularity, in 2006, it could 
legitimately be said to have reflected the sociological reality of the Celtic Tiger economy. It was located at the intersection of important developments in the Irish workforce; in the emergent globalising food industry; and in the reorganisation and consolidation of the petrol station and convenience retail businesses; in an economy that was built - literally - on an unsustainable property boom. At the same time the ingredients of the JBR reflected a 'tradition' that had developed over less than a hundred years - the 'Full Irish Breakfast' - but one that has attained an important cultural and economic value through commodification in the tourist industry.

6.2 Key elements of the JBR are dependent on specific technologies that have emerged in recent years, most importantly the par-bake system (which incorporates a distribution network, a new internal geography of retail stores and a particular 'oven' technology, which I have not explored in this particular paper, but which would also merit further study). The technology of road systems (in which the Irish state and EU have made very significant investments); car-based commuting and the reshaping of petrol forecourts are also an important part of the story. The technologies of meat production, increasingly a global industry, arguably have not impacted greatly on 'traditional' pork products (such as black pudding or bacon rashers) but, inevitably, science-based improvements in meat output, shelf-life, traceability and so on, have an impact on the pork products that find their way into the JBR.

6.3 Analysis of this apparently ephemeral food item is indicative of many of the features of global capitalism: the creolisation of ingredients; the cross-cultural transfer of technologies and techniques, not least through increasingly transnational food service and ingredients conglomerates; and the connection with local and international mobilities. While the pre-eminence of the JBR in Irish culture has waned, probably never to be recaptured, its rise and fall as a 'national dish' has a lot to say about the broader cultural and economic patterns of Irish society. Arguably it now forms a less remarked but stable part of the Irish foodscape: a routine and accepted consumption item: a status reflected by its 'endorsement' by the National Roads Authority.

6.4 A sociological lens is rarely applied to breakfast and its globally quite diverse expressions. In this article I have attempted to place the emergence of the JBR - one type of 'Irish breakfast' experience within a sociological framework that suggests the complexity of factors that can contribute to the emergence of a specific food product; conversely, starting from the point of a single commodity we can trace the structures and processes, historical, technological and economic, that combine to shape our society. There is great scope to expand on any of the factors that have contributed to the emergence of the JBR, not least an ethnography of everyday consumption would be fascinating and would contribute much to our understanding. But I hope that this article has helped to place analysis of this now rather infamous 'dish', and other contemporary food items/products, on the sociological menu of the future.

\section{References}

AMÁRACH CONSULTING (2007) From revolution to evolution: The eating out market in Ireland. A food futures study for ARAMARK/Campbell Catering.

<http://www.amarach.com/assets/docs/Food\%20Futures\%20Report\%202007.pdf>

BERRY, D. (2010) The Irish shopper landscape. . Presentation to Bord Bia Irish and UK Retail Seminar < http://www.bordbia.ie/eventsnews/ConferencePresentations/IrishandUKRetailSeminar2010/1.\%20The\%20Irish\%20Shopper\%20Landscape\%20\%20David\%20Berry,\%20Kantar\%20Worldpanel.pdf >

BORD BIA [Irish Food Board] (2010) Out of home breakfast research.

<http://www.bordbia.ie/industryinfo/publications/bbreports/FoodserviceReports/Out\%20of\%20Home\%20Breakfast\%20Report\%20$\% 20 F$ ebruary\%202010.pdf>

BOUCHER-HAYES, P. \& S. CAMPBELL (2009) Basket case: What's happening to Ireland's food? Dublin: Gill and Macmillan.

BRADLEY, A. (2005) 'Forecourt food from new fashion to new fuel'. Checkout, October

BROOMFIELD, A. (2007) Food and cooking in Victorian England: A history. Westport CT: Greenwood.

'CARROLL CUISINE BACK IN BUSINESS', Offaly Express, 23 December 2008 <http://www.offalyexpress.ie/business/Carroll-Cuisine-moves-to-top.4817990.jp>

CARSWELL, S. (2007) 'King of the forecourt' Irish Post 22 July.

$<$ http://www.thepost.ie/story/text/cwojcwsney/>

CLARKSON, L. \& E. CRAWFORD (2001) Feast and famine: A history of food and nutrtion in Ireland. Oxford: Oxford University Press.

CSO [Central Statistics Office Ireland] (2006) Quarterly National Household Survey Q2 2006.

<http://www.cso.ie/releasespublications/documents/labour_market/2006/qnhs_q22006.pdf>

CSO [Central Statistics Office Ireland] (2010a) Quarterly National Household Survey Q3 2010.

<http://www.cso.ie/releasespublications/documents/labour_market/2010/qnhs_q32010.pdf>

CSO [Central Statistics Office Ireland] (2010b) Seasonally Adjusted Standardised Unemployment Rates. <http://www.cso.ie/statistics/sasunemprates.htm>

CSO Central Statistics Office Ireland (2010c) Population and Migration Estimates April 2010

<http://www.cso.ie/releasespublications/documents/population/2010/popmig_2010.pdf>

CUISINE DE FRANCE (nd) Significant dates in the history of Cuisine de France.

<http://www.cuisinedefrance.ie/intro/intro hist.htm>

DEN HARTOG, A. (1995) Food, technology, science and marketing: European diet in the twentieth century. East Lothian: Tuckwell Press.

FISCHLER, C. \& E. MASSON (2008) Manger: Français, Européens et Américains face à l'alimentation. Paris: Odile Jacob.

GARD, M. \& J. WRIGHT (2005) The obesity epidemic: Science, morality amd ideology. Oxford: Routledge.

GOVERNMENT OF IRELAND (2005) Retail planning: Guidelines for planning authorities. Dublin: Stationery Office.

<http://www.environ.ie/en/Publications/DevelopmentandHousing/Planning/FileDownLoad,1613,en.pdf>

GOVERNMENT OF IRELAND (2010) Food harvest 2020: A vision for Irish agri-food and fisheries. Dublin:

Department of Agriculture, Fisheries and Food. <http://www.agriculture.gov.ie/media/migration/agri-

foodindustry/foodharvest2020/2020FoodHarvestEng240810.pdf> 
HARDING, M. (2008) 'Lessons from a chance meeting with a woman in a cafe'. Irish Times, 21 November 2008, p. 17.

IUNA [Irish Unversities Nutrition Alliance] (2001) North/south Ireland food consumption survey. Dublin: IUNA. <http://www.iuna.net/>

KITCHIN, R., J. GLEESON, K. KEAVENEY \& C. O'CALLAGHAN (2010) A haunted landscape: Housing and ghost estates in post-Celtic Tiger Ireland. NIRSA Working Paper 59. National University of Ireland, Maynooth, National Institute for Regional and Spatial Analysis.

<http://www.nuim.ie/nirsa/research/documents/WP59-A-Haunted-Landscape.pdf>

LEACH, H. (2010) 'The Pavlova wars: How a creationist model of recipe origins led to an international dispute'. Gastronomica 10 (2), pp. 24-30. [doi:10.1525/gfc.2010.10.2.24]

MAROUKIAN, F. (2009) The United States of sandwiches (part 1). Unbreaded [blog] <http://unbreaded.com/2009/05/14/the-united-states-of-sandwiches-part-1/>

MARTIN, J. (2004) Kneading identities: Irish students and the appropriation of food symbolic properties. $\mathrm{PhD}$ thesis, Department of Anthropoogy, National University of Ireland Maynooth.

MCWILLIAMS, D. (2005) The Pope's children: Ireland's new elite. Dublin: Gill and Macmillan.

MORGAN K, MCGEE H, WATSON D, PERRY I, BARRY M, SHELLEY E, HARRINGTON J, MOLCHO M, LAYTE R, TULLY N, VAN LENTE E, WARD M, LUTOMSKI J, CONROY R, BRUGHA R (2008). SLÁN 2007: Survey of lifestyle, attitudes and nutrition in Ireland. Dublin: Department of Health and Children. <http://www.slan06.ie/SLAN2007MainReport.pdf>

MILLER, D. (2010) Stuff. Cambridge: Polity.

O'CONNOR, D. (2003) 'Never mind the bed - where's the breakfast?' Irish Times, 7 August 2003, p. 13.

O'CONNOR, K. (2006) The English breakfast: The biography of a national meal with recipes. London: Kegan Paul.

PAKISTAN DAILY 'Indians boil over Scottish bid to patent chicken tikka masala'. <http://www.daily.pk/? $\mathrm{p}=8103>$

PILCHER, J. (2008) Taco Bell, Maseca and Slow Food: A postmodern apocalypse for Mexico's peasant cuisine? In C. Counihan \& P. van Esterik (eds) Food and culture: A reader [2 ${ }^{\text {nd }}$ ed]. London: Routledge.

POLLAN, M. (2007) The omnivore's dilemma: The search for a perfect meal in a fast-food world. London: Bloomsbury.

'ROBIN COOK'S CHICKEN TIKKA MASALA SPEECH', Guardian,19 April 2001.

<http://www.guardian.co.uk/world/2001/apr/19/race.britishidentity>

RTE [Radio Teilifís Éireann] (2006) Excerpt from Late late show: 'Dixie Walsh' and Jumbo Breakfast Roll <http://www.rte.ie/tv/latelate/20060106.html>

RUGKÅSA, J., K. BALANDA \& O. WALSH (2006) Food culture in rural Northern Ireland: Results from an exploratory ethnographic study undertaken in the 'Decent Food for All (DFfA)' study areas. Institute of Public Health in Ireland.

<http://www.publichealth.ie/files/file/The\%20food\%20culture\%20in\%20rural\%20Northern\%20lreland\%20IPH\%20_fin_\%20Jul\%2006.pdf> SEXTON, R. (1998) A little history of Irish food. Dublin: Gill and Macmillan.

SHARE, P. (2008) JBR. In M.P. Corcoran \& P. Share (eds) Belongings: Shaping identity in modern Ireland. Dublin: Institute of Public Administration. [Irish Sociological chronicles vol. 6].

SHOVE, E., M. WATSON, M. HAND \& J. INGRAM (2007) The design of everyday life. Oxford: Berg.

STEEL, C. (2009) Hungry city: How food shapes our lives. London: Vintage.

SWAIN, G. (2010) Servicing the Irish convenience retail sector. [conference presentation] <http://www.bordbia.ie/eventsnews/ConferencePresentations/ServicinglrishConvenienceRetailSector2010/>

THE FUTURES COMPANY/BORD BIA (2009) Cultural connections: Improving local marketing execution through an understanding of how the consumer lifestyle trends are playing out across different cultures. [conference presentation]

<http://www.bordbia.ie/aboutus/publications/Documents/Cultural\%20Connections\%20-

\%20Improving\%20local\%20marketing\%20through\%20understanding\%20Consumer\%20Lifestyle\%20Trends.pdf>

WICKHAM, J. (2006) Gridlock: Dublin's transport crisis and the future of the city. Dublin: Tasc/New Island.

WILLS, W., K. BACKETT-MILBURN, S. GREGORY \& J. LAWTON (2007) ' "If the food looks dodgy I

dinnae eat it": teenagers' accounts of food and eating practices in socio-economically disadvantaged families'. Sociological Research Online 13(1)15 doi:10.5153/sro.1681 <http://www. socresonline.org.uk/13/1/15.html>

WILSON, B. (2010) Sandwich: A global history. London: Reaktion. 